\title{
Epidemiology of Eastern Massasauga (Sistrurus catenatus) Snakebites in the Great Lakes States, 1800-2015
}

\author{
Dennis K. Wasko, $\mathrm{PhD}^{1}$; Stephan G. Bullard, $\mathrm{PhD}^{1}$; Thomas F. Beauvais ${ }^{2}$ \\ ${ }^{1}$ Hillyer College, University of Hartford, West Hartford, Connecticut; ${ }^{2}$ Ann Arbor, Michigan
}

\begin{abstract}
Introduction-The eastern massasauga rattlesnake (Sistrurus catenatus) has the northernmost distribution of any venomous snake in the United States and presents a potential, but little-studied, risk to humans.

Methods-We quantified the reported incidence of massasauga bites to humans in the Great Lakes states by searching historic and contemporary media reports between 1800 and 2015 .

Results-We identified 848 reported massasauga bites across the region, most of which were concentrated along the border of Indiana and Michigan. The number of bites per decade increased into the late 1800 s as human population increased; it then declined sharply in the 1900s, likely owing to declining massasauga population and habitat. The majority of bites were to adult males. There was no relationship between victim sex and age or activity when bitten. Most bites resulted from snakes the victims were unaware of, usually when individuals accidentally put their hands or feet near an unseen snake. Many bites, however, resulted from people intentionally interacting with a massasauga, such as attempting to capture or kill it. Fatality rates were lower among men than among women and were lower in adolescents than older or younger victims. No fatalities from massasaugas were reported after 1935 .

Conclusions-Fatality rates from massasauga bites reported herein should be interpreted with caution owing to the nature of the data we collected. In the modern era, massasauga bites are generally considered neither common nor life-threatening, although our findings suggest that historically they may have been both more frequent and potentially more dangerous.
\end{abstract}

Keywords: rattlesnakes, pit vipers, envenomation, media reporting

\section{Introduction}

Snakebite represents a substantial risk to human health worldwide, with an estimated 1 to 5 million bites occurring annually. ${ }^{1}$ Although risk of snakebite is much lower in the United States than in other parts of the world, approximately 8000 bites still occur each year in the United States. ${ }^{2}$ The majority of these are bites from rattlesnakes (Crotalus and Sistrurus spp) but also from copperheads, cottonmouths, and coral snakes (Agkistrodon and Micrurus spp) and thus are concentrated in southern and western states where these snakes are most abundant. ${ }^{3}$ The eastern massasauga rattlesnake (Sistrurus catenatus) has the northernmost distribution of all

Corresponding author: Dennis K. Wasko, PhD, Hillyer College, University of Hartford, Mathematics and Science, 200 Bloomfield Ave, West Hartford, CT 06117; e-mail: wasko@hartford.edu.

Submitted for publication July 2020.

Accepted for publication March 2021. venomous snakes in North America, ranging into the midwestern United States and southern Canada, regions where snakebite may not always be thought of as a serious threat.

Eastern massasaugas are found predominantly east of the Mississippi River across the Great Lakes region (Illinois, Indiana, Michigan, Ohio, Wisconsin, and southern Ontario), with some occurrence along the western edge of Iowa and small pockets extending into western New York and Pennsylvania. It was historically found in western Missouri and Minnesota but is now considered extirpated in both states. The species is in decline across its range, likely owing to a combination of habitat loss and fragmentation, road mortality, and direct persecution by humans. ${ }^{4}$ Deliberate, widespread killing of massasaugas was once common, ${ }^{5}$ but currently $S$ catenatus is legally protected as a species of "special concern" in Michigan and as endangered in every other state in which it occurs. Sistrurus catenatus was formerly classified as 1 


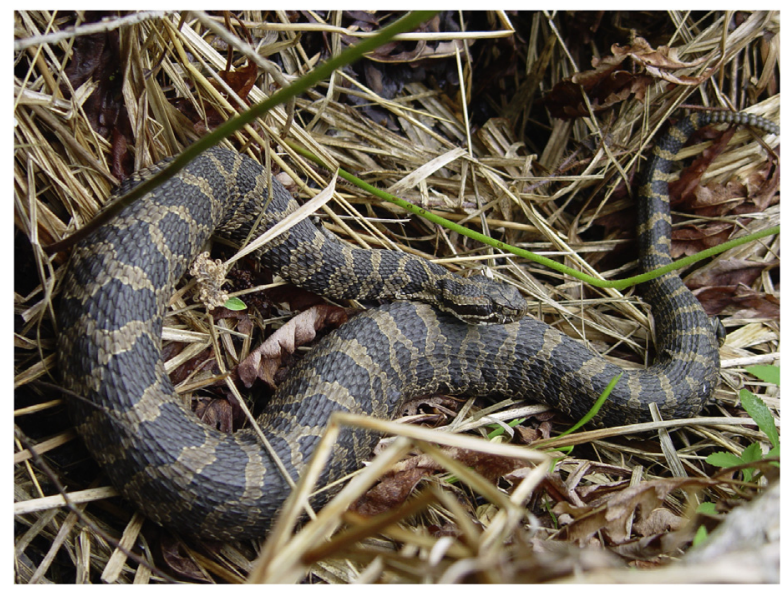

Figure 1. Eastern massasauga rattlesnake, Sistrurus catenatus. Photograph by Bruce Kingsbury, used with permission.

of 3 massasauga subspecies, but it is now generally considered to be distinct from the western and desert massasauga ( $S$ tergeminus tergeminus and $S t$ edwardsii), ${ }^{6,7}$ which are found from Nebraska and Missouri southwest into Arizona and northern Mexico.

Sistrurus catenatus is a moderately sized $(55-80 \mathrm{~cm}$ mean adult total length) ${ }^{8}$ and cryptically colored pit viper, generally similar to the larger and more familiar Crotalus rattlesnakes. Its color pattern is a drab tan or gray base with darker blotches along the sides and back (Figure 1). It is sometimes colloquially known as the swamp rattlesnake owing to its strong association with wet, marshy habitats. ${ }^{9}$ When approached by humans, eastern massasaugas most often either rely on camouflage to remain unseen or quietly retreat; less frequently they may rattle in warning. They rarely attempt to bite unless restrained or physically disturbed. ${ }^{10}$ Owing to their rarity in many locations, their reclusive nature, their wetland habitat preference, and the difficulty of detecting individuals, ${ }^{11}$ human interactions with massasaugas are more limited than with many rattlesnake species. However, unintentional contact between humans and massasaugas (eg, stepping on or putting hands near an unseen snake) may elicit a defensive strike. Defensive bites from massasaugas present a low venom yield, but $S$ catenatus venom is more potent than some larger Crotalus rattlesnakes and these bites can be medically significant. ${ }^{12-14}$

Many analyses of US snakebites rely on data collected from medical entities such as emergency departments and poison control centers. ${ }^{15-17}$ Although highly valuable, these sources provide only contemporary accounts and often only clinical data. Popular media such as newspapers represent a useful supplement-albeit one with limitations-to these traditional data sources because they chronicle incidence before the existence of such medical entities and often contain additional details surrounding the actual bite occurrence. ${ }^{3}$

To gain broader historical insight into human envenomations by the eastern massasauga, we assessed both contemporary and historical accounts of snakebites reported in popular media. Here, we document media-reported bites to humans by eastern massasaugas, focusing on the core of their range in the Great Lakes region of the United States (Illinois, Indiana, Michigan, and Ohio) from 1800 to 2015. Specifically, we identified the geographic locations of bites, the temporal distribution of bites both over the study period and seasonally, the activity of victims while bitten, the demography of bite victims, and the reported fatality rate of massasauga bites.

\section{Methods}

Institutional review board evaluation was not sought for this study because it did not involve research on human or animal subjects.

\section{DATA COLLECTION}

From 2002 to 2017, regular searches were conducted on the digitized newspaper databases www. newspaperarchive.com and www.newspapers.com. Additional databases, including the United States Library of Congress "Chronicling America" collection (mostly for historic accounts) were also periodically searched, and area-specific searches were conducted at regional sources such as Central Michigan University's Clarke Library and city libraries across each study state. In some cases, older reports had information missing from digitized versions, so these were double-checked by microfilm.

Searches were constrained to the word "rattlesnake." Additional search terms (eg, "rattle snake" and colloquial names) did not return appreciable additional results. Search results were then manually sorted to include only cases that contained an actual snakebite report and to screen out duplicate reports of the same case. Species identification was usually confirmed by the use of the common name "massasauga" or by geographic location. In some cases from areas in which massasauga and timber rattlesnake (Crotalus horridus) populations may overlap currently or historically (eg, southern Ohio or western Illinois), it was not possible to definitively ascertain the species responsible, so these cases were excluded. For each case of massasauga bite, we recorded (when possible) the date and time of the bite, county and township where the incident occurred, sex and age of the victim, whether the bite was fatal, and what the victim was doing when bitten, including whether they seemed 
Table 1. The number of human bites by massasaugas identified from popular media reports from 1800-2015

\begin{tabular}{lccc}
\hline State & Bites $(n)$ & Fatalities $(n)$ & Fatality rate $(\%)$ \\
\hline IL & 70 & 25 & 36 \\
IN & 304 & 38 & 13 \\
MI & 416 & 46 & 11 \\
OH & 58 & 9 & 16 \\
\hline Total & 848 & 118 & 14 \\
\hline
\end{tabular}

aware of the snake's presence. Where actual victim age was not available, we attempted to infer general age classes of child (aged $12 \mathrm{y}$ or under), adolescent (12-17 y) or adult (18 y or over).

\section{ANALYSIS}

To assess the geographic distribution of massasauga bites, the location of each bite report was determined to the county level where possible. For each state, we then determined both the overall number of snakebites and the number of fatal bites reported during all years collectively. To assess long-term temporal patterns of snakebite, we determined the number of overall bites and number of fatal bites reported during each decade of the study, collectively across all 4 states. The seasonality of bites was addressed by determining the number of bites that occurred during each month, collectively across all states and years.

Victim demography (sex, age class) and activity when bitten were analyzed across all states and years collectively. Possible association between victim sex and age class or between victim sex and activity when bitten was analyzed using $\chi^{2}$ tests. Possible associations between fatality rate and state, victim sex, and victim age class were also analyzed using $\chi^{2}$ tests. For all tests we used $P \leq 0.05$ as an indicator of statistical significance.

Maps were created in Adobe Photoshop CS5 (Adobe Systems Inc, San Jose, CA). Statistical analyses were performed in Systat 12.0 (Systat Software Inc., Chicago, IL). Figures were created in Excel 2019 (Microsoft, Redmond, WA). Estimated human population during the study period was obtained from United States Census Bureau data (www.census.gov).

\section{Results}

We identified a total of 848 individual reports of snakebites in humans that could be reliably classified as massasauga bites (Table 1). Searches also identified an additional 152 bites to animals (most often horses, dogs, or cows), 836 reports of snakes being deliberately killed,
252 reports in which snakes were observed but not disturbed, and 535 cases in which snakes were collected (eg, for museum specimens, pets, relocation, or for unreported reasons), and 208 additional anecdotes regarding massasaugas, but all of these are excluded from the current analysis. Bites were located across the study region within massasaugas' reported range, with the greatest concentration along the border of Indiana and Michigan near Lake Michigan (Figure 2).

Michigan had the greatest number of reported bites at 416 and Ohio the fewest at 58 (Table 1). Across all states collectively, the number of bites initially increased with growing human population with a peak in the late 1800s and then declined dramatically into the 1900s (Figure 3). The number of reported fatalities was generally low relative to number of bites, although $36 \%$ of 70 bites in Illinois were fatal. The highest number of fatal bites occurred in the 1880s, with 25 fatal bites during the decade. No human fatalities from massasauga bites were reported after 1935.

Seasonality of bites strongly coincided with the warmer months, when snakes in temperate regions are more active (Figure 4). The few bites that were reported in colder winter months were from snakes that were inside buildings or were apparently disturbed while hibernating.

Most victims were bitten when they accidentally touched or placed their hands near a snake $(42 \%)$, followed by stepping on or near an unseen snake $(41 \%)$ (Figure 5). Victims who were aware of the snake were more often bitten while intentionally handling or attempting to kill it. However, we determined activity and awareness separately because they were not universally related-for example, there were reports of individuals being bitten while stepping over a snake they knew was present or intentionally grabbing a snake they had accidentally misidentified as an inanimate object.

Most cases (98\%) reported the victim's sex, but only 316 (37\%) specified the victim's exact age. An additional 106 cases directly implied age class (eg, "a little girl," "a middle aged man"). For the remainder, we attempted to infer age class based on context (eg, a "man" bitten while at work, the victim referred to as "Mrs."). Cases in which victim sex or age could not be reliably determined $(n=49)$ were excluded from analysis. Our review found there were more bites to males than females across all age classes (Figure 6) but that there was no significant association between sex and age class $\left(\chi^{2}=0.158, P=0.92\right)$ or sex and activity when bitten $\left(\chi^{2}=5.85, P=0.12\right)$.

Of all massasauga bites, $122(15 \%)$ were reported as being fatal, 447 (53\%) were explicitly reported as nonfatal, and the eventual outcome was not included for 


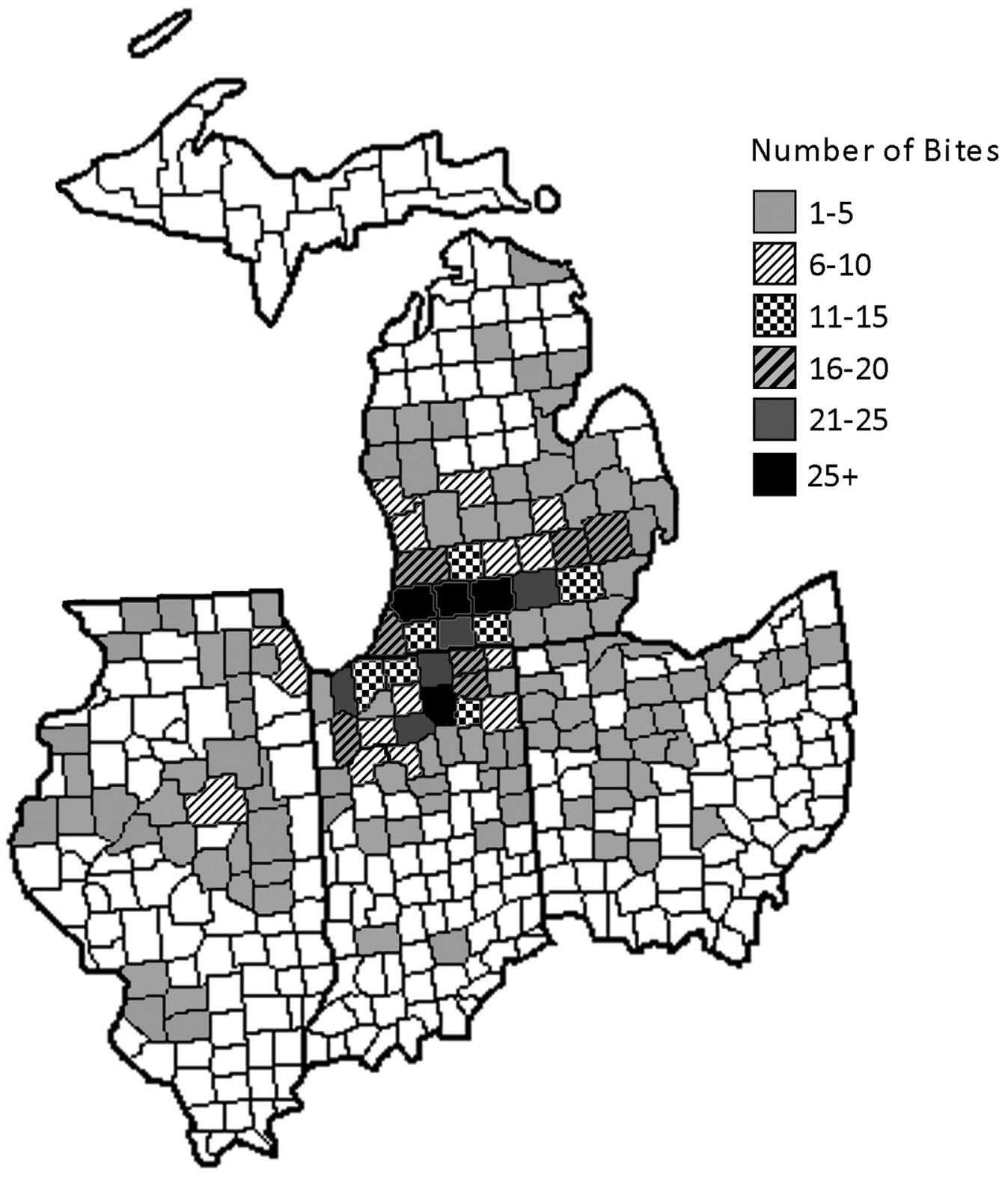

Figure 2. Map of all massasauga bite reports that could be identified to the county level $(n=847)$.

$279(33 \%)$. In assessing fatality rates, we assumed that bite victims survived unless specifically stated otherwise. Fatality rate was significantly associated with state $\left(\chi^{2}=33.21, P<0.01\right)$. Illinois had relatively few bites at 70 , but had 25 fatalities, nearly triple the rate of other states. Fatality rates were significantly higher for women than for men (20 and $11 \%$, respectively; $\chi^{2}=14.58$, $P<0.01)$. Fatality rate was also significantly associated with age class $\left(\chi^{2}=6.07, P=0.047\right)$, with a lower fatality rate among adolescents (10\%) than among children $(20 \%)$ or adults $(29 \%)$.

\section{Discussion}

Media searches revealed a surprisingly large number of massasauga bites considering the current perception that massasaugas are both uncommon and reluctant to bite. Owing to the nature of our media-reported data, our results will be influenced by both the actual number of snakebites that occurred and by the availability, trends, and biases of media reporting over the study period. Therefore, our results should not necessarily be considered a direct measure of the actual number of snakebites 


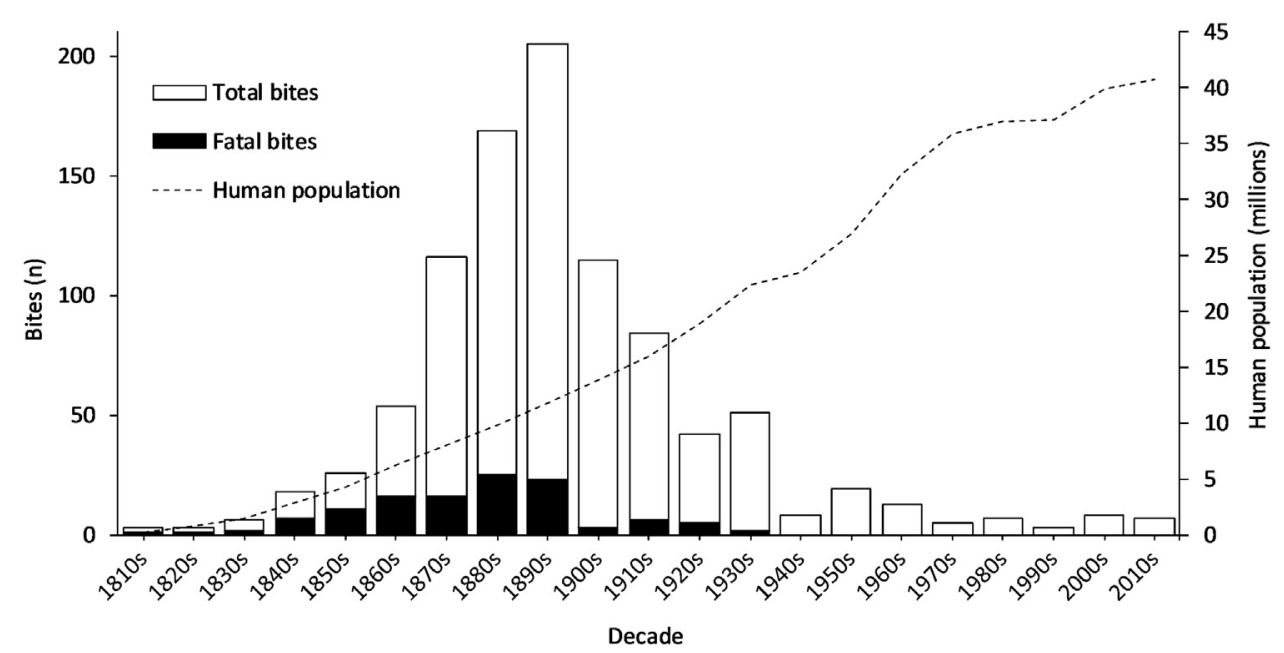

Figure 3. The number of total massasauga bites to humans, number of fatal bites, and estimated human population reported during each decade. Data are collective for all 4 study states (Illinois, Indiana, Michigan, and Ohio).

that occurred. They can, however, reveal spatiotemporal trends and human factors associated with massasauga bites.

Bites were distributed widely across the study area, but a very strong cluster was found around the border of northern Indiana and southwestern Michigan. The counties in this region are in the center of massasaugas' geographic range, and many saw a rapidly increasing human population in the late 1800s. These 2 states also had a much higher number of bites overall than Illinois and Ohio. We identified no bites from the upper peninsula of Michigan, which is predominantly rural and sparsely populated by humans even at the current time. There were also no bites identified from the southernmost counties across the entire region, a boundary that largely

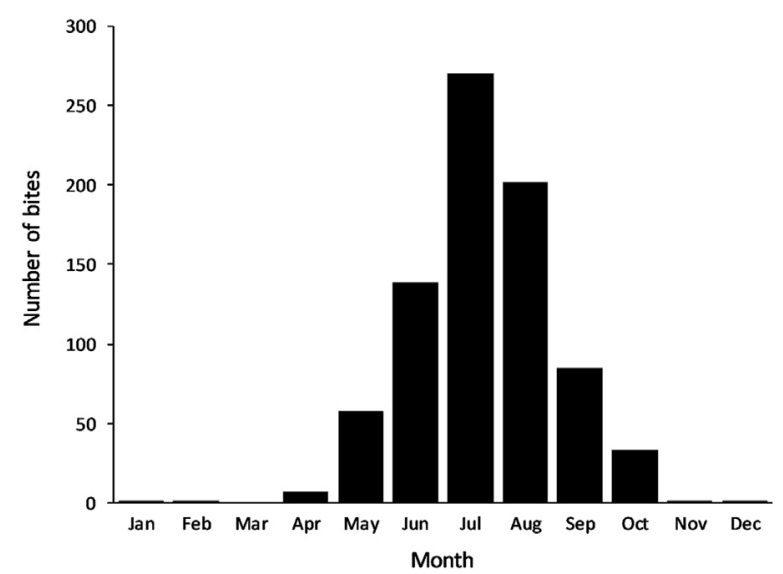

Figure 4. The total number of massasauga bites to humans reported in each month, collectively across all years and states, for cases in which month could be determined $(n=797)$. coincides with the reported southern limit of the massasauga's range.

Seasonally, bites predominantly occurred during the warmest summer months. This is not surprising for an ectothermic species in a northern, strongly temperate region and is characteristic of venomous snakebites across much of the United States. ${ }^{18}$ Although some bites were reported during colder months, these typically resulted from humans disturbing a sheltered snake (eg, "ran into a nest of rattlers" while plowing) or rarely from a snake that had apparently wandered into a building, possibly for warmth (eg, several reports of a snake being found in one's bed).

The number of bites reported was extremely low from 1800 through the 1830s, with fewer than 5 bites identified in each decade. This may be due to the low human population during this period (less than 5 million across all 4 states) or the low availability of media outlets to report snakebites in developing rural areas. The number of bites increased in each decade to a peak of 182 bites in the 1890s and then decreased sharply to no more than 5 bites per decade since the 1940s. This pattern could be explained initially by increasing human population and development across the region (which continues to the current day) leading to increased encounters with massasaugas, and the later decrease in bite occurrence could be explained by declining snake population as a result of that development.

The majority of bite victims (77\%) were unaware of the snake when they were bitten, with the most frequent activities associated with snakebite being accidentally stepping on or near a snake or accidentally grabbing or putting hands near a snake. Only $16 \%$ of victims were reportedly aware of the snake before they were bitten. 


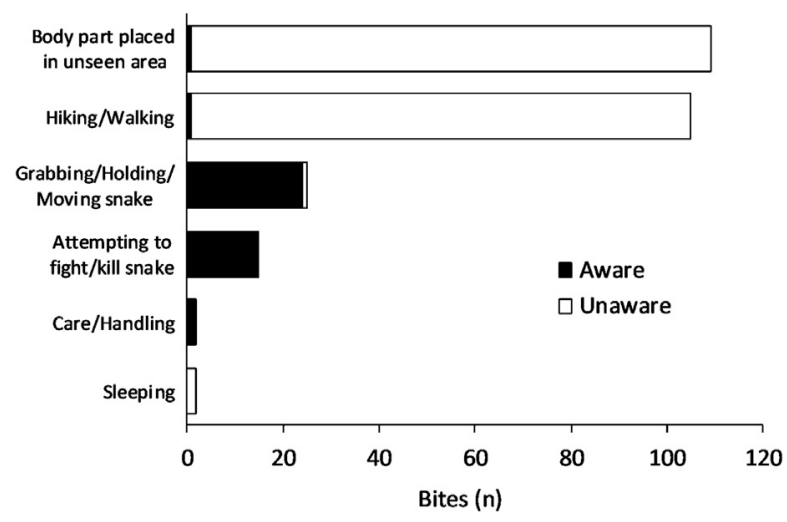

Figure 5. Victim's activity when bitten and awareness of the massasauga's presence before being bitten, for cases in which such information could be determined $(\mathrm{n}=258)$.

These bites almost always resulted from the person deliberately interacting with the snake, such as attempting to move, capture, or kill it. Although some studies have reported that most human snakebites occur from such intentional interactions, ${ }^{19,20}$ our data concur with other media-based studies finding that most bites are accidental. ${ }^{3}$ The reason for this discrepancy is unclear, although it could partially be explained by the information victims are willing to provide to medical personnel in a confidential setting (the data on which many snakebite studies are based), versus that provided to public media outlets. Few data available to address this idea.

There were more massasauga bites to male than female victims across all age classes, and the majority of bites were to adults. Age data proved difficult to definitively quantify; in many cases we had to infer the victim's age as adult, so some cases may have been miscategorized (child vs adolescent, adolescent vs adult). However, these results are consistent with reviews finding that most snakebites in the United States are to young men. ${ }^{15,20}$

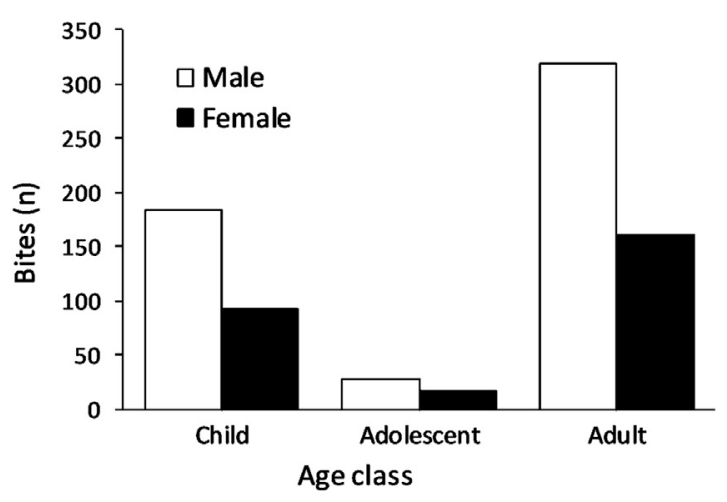

Figure 6. Age class and sex of massasauga bite victims for cases in which both could be determined $(n=799)$.
We found no association between sex and either age class or activity when bitten. This indicates that neither sex was more likely than the other to be bitten at a given age or during any particular activity, in contrast to a previous study. ${ }^{3}$ The limited details provided by historical data hindered rigorous demographic analysis. We also cannot discount the possibility of reporting bias, with bites considered more newsworthy if they occurred to certain groups (eg, children) or under unusual or dramatic circumstances (eg, several individuals bitten while in bed or while "killing" a "nest" of massasaugas). It is also possible that changes in cultural or social norms between the early 1800s and early 2000s affected the exposure of different age classes and sexes to the risk of snakebite. For example, it is clear from the reports that people of both sexes and all ages spent a great deal of time outdoors in the early 1800 s.

Trends in fatal massasauga bites largely followed the patterns of snakebites overall, with a similar increase into the late $1800 \mathrm{~s}$ as human population increased and a dramatic decrease into the 1900s. No fatalities due to massasaugas were reported after the 1930s. This decline in fatalities likely coincides with the increasing availability of medical care over that time period and the commercial production of crotaline antivenom beginning in 1927. Adolescents had the lowest fatality rate, which corresponds to a greater susceptibility of very young and old victims. ${ }^{15,16}$

\section{LIMITATIONS}

The data on which this study is based were drawn from a wide variety of informal news outlets across more than 2 centuries, often from rural and sparsely populated areas. Many bites likely went unreported to any media outlet, and there was little uniformity in the information included for cases that were reported. For example, we were able to reasonably infer a general age class for most (94\%) bite victims, but victim age was only explicitly stated for about a third of cases.

Although many of the trends in massasauga envenomations illustrated here seem reasonable compared to other published snakebite studies, ${ }^{3,15}$ fatality data in particular should be interpreted with caution. Reporting bias may again play a role because fatal snakebites will likely always be considered more notable than nonfatal bites. Additionally, a third of all reports did not include the eventual fate of the victim. Even assuming that all of these victims survived, calculated fatality rates from massasaugas in some states were substantially higher than those reported from other developing areas of the world that feature highly venomous species such as mambas, cobras, and vipers and where immediate 
medical care was similarly unavailable. ${ }^{21,22}$ Fatality rates were also far higher than those from the modern United States, with more robust media reporting. ${ }^{3}$ The fatality data presented in this paper are therefore useful for assessing general temporal, geographic, and demographic trends, but specific individual mortality figures (eg, a reported $36 \%$ fatality rate in Illinois) should be viewed with caution.

\section{Conclusions}

Currently, massasauga snakebites are considered dangerous but are rarely life-threatening or ultimately fatal. ${ }^{23}$ Historically, however, massasauga snakebites appear to have been much more common and potentially much more dangerous owing to the unavailability of rapid medical care. Specifically, we found that the number of massasauga bites and bite fatalities increased to a peak in the late 1800 s with rising human population and subsequently decreased dramatically into the 1900s. The data herein should be interpreted with caution owing to the nature of popular media reporting and are best used to consider trends rather than quantify actual snakebite statistics. Overall, our results concur with studies finding that most snakebite victims are adult males and that most snakebites are the result of accidental rather than deliberate interaction with a snake.

Author Contributions: Study concept and design (TFB); acquisition of the data (TFB); analysis of the data (DKW, SGB); drafting of the manuscript (DKW); critical revision of the manuscript (DKW, SGB); approval of final manuscript (DKW, SGB, TFB).

Financial/Material Support: None.

Disclosures: None.

\section{References}

1. Kasturiratne A, Wickremasinghe AR, de Silva N, Gunawardena NK, Pathmeswaran A, Premaratna R, et al. The global burden of snakebite: a literature analysis and modeling based on regional estimates of envenoming and deaths. PLoS Med. 2008;5(11):e218.

2. Gold BS, Dart RC, Barish RA. 2002. Bites of venomous snakes. New Engl J Med. 2002;347(5):347-56.

3. Wasko DK, Bullard SG. An analysis of media-reported venomous snakebites in the United States, 2011-2013. Wilderness Environ Med. 2016;27(2):219-26.

4. Szymanski J, Pollack C, Ragan L, Redmer M, Clemency L, Voorhies K, Jaka J. Status assessment for eastern massasauga rattlesnake (Sistrurus catenatus): SSA Report version 2. Fort Snelling, Minnesota: U.S. Fish and Wildlife Service; 2016.

5. Bushey CL. Man's effect upon a colony of Sistrurus c. catenatus (Raf.) in northeastern Illinois (1834-1975). Bull Chicago Herp Soc. 1985;20(1):1-12.
6. Kubatko LS, Gibbs HL, Bloomquist EW. Inferring specieslevel phylogenies and taxonomic distinctiveness using multilocus data in Sistrurus rattlesnakes. Syst Biol. 2011;60(4):393-409.

7. Ryberg WA, Harvey JA, Blick A, Hibbitts TJ, Voelker G. Genetic structure is inconsistent with subspecies designations in the western massasauga Sistrurus tergeminus. J Fish Wildl Manag. 2015;6(2):350-9.

8. Minton Jr SA. Sistrurus catenatus. Catalog of American Amphibians and Reptiles. 1983;332:1-2.

9. Bailey RL, Campa III H, Bissell KM, Harrison TM. Resource selection by the eastern massasauga rattlesnake on managed land in South Michigan. J Wildlife Manage. 2012;76(2):414-21.

10. Prior KA, Weatherhead JP. Response of free-ranging eastern massasauga rattlesnakes to human disturbance. J Herpetol. 1994;28(2):255-7.

11. Bartman JF, Kudla N, Bradke DR, Otieno S, Moore JA. Work smarter, not harder: comparison of visual and trap survey methods for the eastern massasauga rattlesnake (Sistrurus catenatus). Herpetol Conserv Bio. 2016;11(3):451-8.

12. Schöttler WHA. Toxicity of the principal snake venoms of Brazil. Am J Trop Med Hyg. 1951;31(4):489-99.

13. Christiansen J, Fieselmann J. Massasauga rattlesnake bites in Iowa. Iowa Med. 1993;83(5):187-91.

14. Gibbs HL, Mackessy SP. Functional basis of a molecular adaptation: prey-specific toxic effects of venom from Sistrurus rattlesnakes. Toxicon. 2009;53(6):672-9.

15. O'Neil ME, Mack KA, Gilchrist J, Wozniak EJ. Snakebite injuries treated in United States emergency departments, 2001-2004. Wilderness Environ Med. 2007;18(4):281-7.

16. Campbell BT, Corsi JM, Boneti C, Jackson RJ, Smith SD, Kokoska ER. Pediatric snakebites: lessons learned from 114 cases. J Pediatr Surg. 2008;43(7):1338-41.

17. Spyres MB, Ruha AM, Kleinschmidt K, Vohra R, Smith E, Padilla-Jones A. Epidemiology and clinical outcomes of snakebite in the elderly: a ToxIC database study. Clin Toxicol (Phila). 2018;56(2):108-12.

18. Seifert SA, Boyer LV, Benson BE, Rogers JJ. AAPCC database characterization of native U.S. venomous snake exposures, 2001-2005. Clin Toxicol (Phila). 2009;47(4):327-35.

19. Minton SA. Poisonous snakes and snakebite in the US: a brief review. Northwest Sci. 1987;61(2):130-6.

20. Curry SC, Horning D, Brady P, Requa R, Kunkel DB, Vance MV. The legitimacy of rattlesnake bites in central Arizona. Ann Emerg Med. 1989;18(6):658-63.

21. David S, Matathia S, Christopher S. Mortality predictors of snake bite envenomation in southern India - a ten-year retrospective audit of 533 patients. J Med Toxicol. 2012;8(2):118-23.

22. Tagwireyi D, Nhachi CFB, Ball D. Snakebite admissions in Zimbabwe: pattern, clinical presentation and management. Cent Afr J Med. 2011;57(5-8):17-22.

23. Sing K, Erickson T, Aks S, Rothenberg H, Lipscomb J. Eastern massasauga rattlesnake envenomation in an urban wilderness. J Wilderness Med. 1994;5(1):77-87. 